\title{
"Mobile" Leprosy Control in the Luapula Province of Zambia*
}

\author{
B. JOGAN \\ Leprosy Specialist, Ministry of Health, Lusaka, Zambia \\ and
}

I. ROGERS

L.eprosy Control Officer, British L.eprosy Relief Association (L.EPRA)

\begin{abstract}
This is a brief report on the progress of a LEPRA Project in the Luapula Province of Zambia. The period from the start of the project in September, 1970, until the end of 1972 is reviewed. The operational methods employed are described and the results of the projects so far are reported, with pertinent statistics and comments.
\end{abstract}

\section{Introduction}

The first leprosy mobile treatment compaign in Zambia was introduced in the Eastern Province in 1968 as a joint venture of the Zambian Ministry of Health and the British Leprosy Relief Association. The Association provided an experienced Leprosy Control Officer, Mr A. H. Drake, and 2 Land Rovers. The Ministry provided 2 Medical Assistants, a Tuberculosis-Leprosy Preventive Assistant, and their accommodation, as well as funds for the running and maintenance of the vehicles. The results of the scheme were published in Leprosy Review (1970) 41 , 115-120.

As the mobile treatment scheme in the Eastern Province of Zambia proved to be very successful, it was therefore decided to start a similar venture in the Luapula Province. This Province covers an area of 19.524 sq. miles with an estimated population of some 360,000 in mid-1972; it has pretty good lines of communication, and a reasonable number of Medical Centres in the most thickly populated parts of the Province.

\section{Operational Methods}

In August, 1970, LEPRA provided 2 Land Rovers and the services of Mr I. Rogers, an experienced Leprosy Control Officer, who was transferred from the LEPRA project in Malawi. The Zambian Government provided 2 Medical Assistants, in addition to funds for the running and maintenance of the vehicles.

For practical reasons, the Province was divided into 2 regions and 1 vehicle was based on Mansa, the provincial capital, while the other was based at Kabalenge Leprosy Settlement to provide the services for the northern part of the province. A Medical Assistant was placed in charge of each of these regions, with Mr Rogers

* Received for publication 24 April, 1973. 
in overall charge of the running and extension of the scheme for the whole province.

At the start of the project, it was decided to make some modifications in respect of the project in the Eastern Province where the entire leprosy out-patient treatment was undertaken by the mobile teams. The staff of the Rural Health Centres in Luapula Province remained responsible for the treatment of leprosy patients in their respective clinics, but under the strict supervision of the LEPRA teams. It was envisaged that with the new approach, the local staff would acquire an adequate knowledge of the problems of leprosy and would show more interest in the treatment of the disease. At the same time, such a decision was in line with the general policy of an integrated health service in Zambia.

Once the Project was well under way, mobile treatment runs would be established in those areas of the province having scarce medical facilities in order to bring treatment centres closer to the patients' homes.

\section{Treatment}

It was decided at the beginning of the project that mobile treatment would be dispensed to the patients by intramuscular dapsone injections at 4-week intervals, using disposable syringes. During the period under review not a single case of abscess formation was reported.

\section{Preliminary Work}

During the early stages of the project, the 2 teams visited Rural Health Centres in the province in an attempt to obtain a true picture of the leprosy situation then prevailing. It was very soon discovered that the available figures covering the leprosy situation could not be relied upon. (a) The leprosy registers were in complete disorder, many patients being listed who had not attended for treatment for many years. (b) Owing to the unreliability of the recording system, it was impossible to assess the percentage of attendance for treatment, but we would estimate it to be below 50\%. (c) Many patients listed in the leprosy registers were without any personal records, and therefore, no data were available about the various types of leprosy or when patients had started treatment. (d) At many Rural Health Centres the treatment of leprosy patients was left to orderlies and dressers, who were not qualified to decide the best treatment. (e) The classification of leprosy was frequently left to staff with an inadequate knowledge of the disease. (f) A very high percentage of patients, though listed as "on parole", had not taken treatment for many years, but their names appeared on the register. There were 377 of these patients "on parole".

\section{Case Finding Campaigns}

\section{SCHOOL SURVEYS}

From the early stages of the project it had been decided to start an intensive school survey, and plans were set up accordingly. This was a priority objective for the following reasons: (a) There are no difficulties in the way of schools' medical examinations. (b) From experience gained in previous school surveys in the Eastern Province and elsewhere in Zambia, it was known that school authorities were very cooperative and helpful in carrying out surveys, and attendence for 
TABLE

Out-patients on treatment at 31 December, 1970 (start of LEPRA project)

\begin{tabular}{lccccc}
\hline \multicolumn{1}{c}{ Classification } & Male & Female & $\begin{array}{c}\text { Children } \\
0-14 \mathrm{yr}\end{array}$ & Total & $\begin{array}{c}\text { Distribution } \\
(\%)\end{array}$ \\
\hline $\begin{array}{l}\text { Lepromatous } \\
\text { Borderline }\end{array}$ & 186 & 99 & 2 & 287 & 17.4 \\
$\begin{array}{l}\text { Tuberculoid } \\
\begin{array}{l}\text { Indeterminate and } \\
\quad \text { unclassified }\end{array}\end{array}$ & 249 & 271 & 12 & 532 & 32.2 \\
$\begin{array}{l}\text { Totals } \\
\text { Distribution by age }\end{array}$ & 23 & 394 & 37 & 722 & 43.7 \\
$\quad$ and by sex for adults & $45.3 \%$ & 51 & 37 & 111 & 6.7 \\
\hline
\end{tabular}

N.B. 377 patients were out on parole and are not included in the above figures.

TABLE 2

Out-patients on treatment at 31 December, 1972

\begin{tabular}{|c|c|c|c|c|c|}
\hline Classification & Male & Female & $\begin{array}{c}\text { Children } \\
0-14 \mathrm{yr}\end{array}$ & Total & $\begin{array}{l}\text { Distribution } \\
(\%)\end{array}$ \\
\hline Lepromatous & 241 & 109 & 1 & 351 & 14.3 \\
\hline Borderline & 301 & 283 & 35 & 619 & 25.0 \\
\hline Tuberculoid & 397 & 590 & 270 & 1257 & 51.3 \\
\hline $\begin{array}{l}\text { Indeterminate and } \\
\text { unclassified }\end{array}$ & 39 & 61 & 123 & 223 & 9.1 \\
\hline Totals & 978 & 1043 & 429 & 2450 & \\
\hline $\begin{array}{l}\text { Distribution by age } \\
\text { and by sex for adults }\end{array}$ & $40 \%$ & $42.5 \%$ & $17.5 \%$ & & \\
\hline
\end{tabular}

N.B. 164 patients on parole are included in the above figures.

examination was always very high. (c) With this type of survey it is comparatively easy to assess a valuable and reliable prevalence rate of leprosy in the chosen group.

\section{VILLAGE SURVEYS}

It is well known to leprosy workers that intensive village surveys are a time-consuming exercise, very costly, and require good planning, for the following reasons: (a) It is difficult to obtain correct census figures for areas chosen for the survey. (b) Contacts with local authorities and traditional Chiefs do not always stimulate the hoped-for enthusiasm and cooperation on their part. (c) Prejudices deeply entrenched in the local population play an adverse rôle against a successful response. (Similar difficulties were encountered during village surveys in the Luapula Province.)

Table 4 shows the statistics for village surveys.

\section{Leprosaria}

With the LEPRA project well established in the province, many leprosy patients, who were previously admitted to hospital because they lived far from 
TABLE, 3

Rate in schoolchildren

\begin{tabular}{cccccc}
\hline $\begin{array}{c}\text { Schools } \\
\text { visited }\end{array}$ & $\begin{array}{c}\text { No. of children } \\
\text { examined }\end{array}$ & $\begin{array}{c}\text { Positive } \\
\text { cases }\end{array}$ & Rate & $\begin{array}{c}\text { Doubtful } \\
\text { cases }^{a}\end{array}$ & Rate \\
249 & 65,439 & 418 & 6.39 per 1000 & 555 & 8.48 per 1000 \\
\hline $\begin{array}{c}\text { a Under "doubtful cases" are listed children with undefined skin lesions; these children will be } \\
\text { followed up in future and some of them may develop clear signs of leprosy. }\end{array}$ \\
$\begin{array}{c}\text { TABLE } 4 \\
\text { Age distribution }\end{array}$ \\
\hline $0-15$ years & $15+$ years & Total & No. of cases detected & Rate \\
2256 & 3140 & 5396 & 13 & 2.41 per 1000 \\
\hline
\end{tabular}

TABLE 5

In-patient position on 31 December, 1970

\begin{tabular}{lcccc}
\hline \multicolumn{1}{c}{ Classification } & Under 14 years & Over 14 years & Total & Distribution (\%) \\
Lepromatous & & 88 & 88 & 56.4 \\
Borderline & 1 & 45 & 46 & 29.4 \\
Tuberculoid & 3 & 18 & 21 & 13.4 \\
Unclassified & - & 1 & 1 & 0.6 \\
Totals & 4 & 152 & 156 & \\
Distribution by age & $2.56 \%$ & $97.43 \%$ & & \\
\hline
\end{tabular}

TABLE 6

In-patient position on 31 December, 1972

\begin{tabular}{lcccc}
\hline \multicolumn{1}{c}{ Classification } & Under 14 years & Over 14 years & Total & Distribution (\%) \\
\hline Lepromatous & & 57 & 57 & 52.7 \\
Borderline & 1 & 26 & 27 & 25.0 \\
Tuberculoid & 2 & 19 & 21 & 19.4 \\
Unclassified & - & 3 & 3 & 2.7 \\
Totals & 3 & 105 & 108 & \\
Distribution by age & $2.77 \%$ & $97.22 \%$ & & \\
\hline
\end{tabular}

the nearest treatment point, could be discharged from the Leprosaria to out-patients treatment. It soon became very clear that with the progress of the out-patients treatment programme, one leprosarium in the province was sufficient to provide any necessary hospital accommodation for all in-patients from the entire province. One of the two Leprosy Settlements in the province was, therefore, closed at the end of 1971. (See Tables 5 and 6.) 


\section{Observations}

Comparing the figures in Tables 1 and 2, the following conclusions may be drawn.

(1) In the 2-year period of the LEPRA project the number of leprosy patients in the Province has increased from 2195 to 2450 , but the actual number of patients on active treatment has increased from 1652 to 2286.

(2) During the same period, 370 patients were' released from control, which means that the number of patients on active treatment has increased by 1004 new cases.

(3) Of the total number of patients in the province at the end of $1972,39.3 \%$ are suffering from the infectious type of leprosy, and $60.4 \%$ from the non-infectious type.

(4) Comparing the percentage of the various types of leprosy in the 2 above-mentioned tables, it is easy to see that the number of cases of tuberculoid leprosy has increased in the 2 years under consideration. This is due to the following facts: (i) the adoption of the WHO classification; (ii) to improved recording: and (iii) a higher number of schoolchildren brought under treatment.

(5) There were no base-line data available showing the attendance for treatment before the start of the new project, so that no comparable figures are available Nevertheless, in the 2 mobile runs, where 227 patients are taking treatment, the attendance varies from $75 \%$ to $100 \%$, compared with the attendance rate of $60 \%$ at the static clinics.

\section{Economic Considerations: Cost per Patient}

The current expenditure for the leprosy control programme in Zambia is included in the General Health Budget, and therefore no definite data are available. Nevertheless, an attempt was made a few years ago to ascertain the approximate cost per leprosy patient in the leprosaria and in the out-patient treatment programme.

The average annual cost per patient was as follows:

(1) Liteta Government Leprosy Hospital

(2) Chikankata Mission Leprosy Settlement

${ }^{*} \mathrm{~K} 460.00$

(3) LEPRA Project-Eastern Province

(4) LEPRA Project-Luapula Province

Calculating the average cost per patient, we took into consideration the purchase cost of the Land Rovers, the cost for the running and maintenance of these vehicles (at the rate of $15 \mathrm{n}$ per mile), and staff salaries. The cost of drugs was not included, but this is not of great relevance to the final cost.

The higher average cost per patient in the Eastern Province is due mainly to the mobile treatment introduced throughout the entire province, the greater distances to reach the mobile clinics, and to the smaller number of cases on treatment, whereas in the Luapula Province much of the out-patient treatment was undertaken by the established Rural Health Centre staff, but under the supervision of the LEPRA teams.

It has been proved once again that out-patient treatment is the cheapest way of approach to the treatment of leprosy.

* One Kwacha is equal to $80 \mathrm{p}$. 
It is too early to reach a conclusive judgement about the success or failure of the LEPRA project after 27 months of its operation, but nevertheless, the following are its main achievements so far: (1) We have now reliable statistical data about the prevalence rate of known leprosy patients in the Province. (2) Accurate figures for the prevalence rate of leprosy among schoolchildren in the Province are now available. (3) The attendance for treatment has greatly improved, but we are unable to say exactly by how much owing to the lack of base-line comparable data. In the mobile runs, which care for 227 patients, the attendance is now above $75 \%$. (4) The LEPRA project in the province has proved to be the most economical approach to a successful leprosy control programme. (5) Under the regular supervision of the LEPRA staff, the para-medical staff in the Rural Health Centres have acquired a better knowledge of leprosy and they are now showing more interest in the treatment of leprosy. (6) The patients are aware that a greater interest is being shown in their welfare.

A lot of ground remains to be covered in our fight for the control of leprosy in the Province, but the LEPRA project has shown us the right direction towards achieving this goal. In the next stage of the Project we shall be concentrating on improving the attendance-rate for treatment, the examination of contacts of open cases of leprosy, extending the case-finding campaign in surveys of villages, and the establishment of more mobile-treatment runs in areas with as yet scarce or non-existent facilities.

Comments on Tables 1, 2, 5 and 6 relating to prevalence rates and leprosy indices:

(1) Prevalence rate of known leprosy cases in the Province. Estimated population for mid-year 1970, 349,300; rate, 6.4 per 1000. Estimated population for mid-year 1972, 360,000; rate,7.1 per 1000 .

(2) The case-type rate, i.e. the number of "open cases" per 100 cases of leprosy, for 1970 was $49.6 \%$ (819 out of a total of 1652 cases), and for 1972 it was $39.3 \%$ (970 out of a total of 2450 cases).

(3) Sex and childhood rate of the total number of cases:

Distribution in 1970 viz:

$\begin{array}{cccc}\text { Adults (Male) } & \text { Adults (Female) } & \text { Children } & \text { Total (100\%) } \\ 45.3 \% & 49.3 \% & 5.3 \% & 1652 \text { cases }\end{array}$

The distribution in 1972 was:

$\begin{array}{cccc}\text { Adults (Male) } & \text { Adults (Female) } & \text { Children } & \text { Total (100\%) } \\ 40 \% & 42.5 \% & 17.5 \% & 2450 \text { cases }\end{array}$

(4) The distribution by types of leprosy, sex, and age shown in Tables 5 and 6 is very similar, except for a higher in-patient and out-patient ratio. It is a general trend in leprosy control programmes that, with the expansion of out-patient treatment, the number of in-patients is diminishing. The ratio of in-patients to out-patients in 1970 was 1 in 13, but in 1972 it was 1 in 22 .

(5) A sharp increase is noted in the childhood rate between 1970 and 1972. This is due to intensive surveys undertaken in the schools. For similar reasons, there is a sharp increase in the number of cases of the tuberculoid type of leprosy. This last should be attributed to the greater number of children brought under treatment in the period under review, and also in part to the World Health Organization classification which was adopted by the LEPRA teams. 


\section{Acknowledgements}

We are indebted to the Permanent Secretary of the Zambian Ministry of Health, Lusaka, and to the British Leprosy Relief Association (LEPRA), London, for permission to publish this article.

We also thank Mr S. T. Mkandawire and Mr W. S. Chanda. the two Senior Medical Assistants, for their enthusiastic cooperation in the work described. 